\title{
Mathematical modeling for exploring the effects of overtime option, rework, and discontinuous inventory issuing policy on EMQ model
}

\author{
Singa Wang Chiu ${ }^{\mathrm{a}}$, Hong-Dar Lin ${ }^{\mathrm{b}}$, Chung-Li Chou ${ }^{\mathrm{a}}$ and Yuan-Shyi Peter Chiu ${ }^{\mathrm{b}}$
}

${ }^{a}$ Department of Business Administration, Chaoyang University of Technology, Wufong District, Taichung 413, Taiwan ${ }^{b}$ Department of Industrial Engineering \& Management, Chaoyang University of Technology, Wufong District, Taichung 413, Taiwan

\section{CH R O N I C L E A B S T RA C T}

\begin{tabular}{l} 
Article history: \\
Received August 182017 \\
Received in Revised Format \\
August 252017 \\
Accepted November 152017 \\
Available online \\
November 152017 \\
\hline Keywords: \\
Optimization \\
Replenishment lot-size and \\
shipments \\
Overtime \\
Rework \\
Economic manufacturing quantity \\
Mathematical modeling \\
Discontinuous issuing policy
\end{tabular}

\section{Introduction}

A mathematical modeling is used in this study to explore the effects of overtime option, rework, and discontinuous end-item issuing policy on the economic manufacturing quantity (EMQ) model. Unlike the conventional EMQ model (Taft, 1918) which finds the most economic manufacturing lot size with simple assumptions of perfect product quality and continuous issuing policy; in real world, nonconforming items are sometimes produced, due to diverse unexpected factors in fabrication process (Mak, 1985; Henig \& Gerchak, 1990; Boone et al., 2000; Maddah et al., 2010; Chiu et al., 2015a,b; Kim et al., 2015; Koley et al., 2015; Koren \& Palčič, 2015; Jindal \& Solanki, 2016; Zhang et al., 2016; Dhaiban et al., 2017). Reworking and repairing the nonconforming items can help reduce total manufacturing costs (Yum \& McDowell, 1987; Zargar, 1995; Inderfurth, 2006; Taleizadeh et al., 2010; Chiu et al., 2016a,b; Jawla \& Singh, 2016; Khanna et al., 2017). Besides, when finished items are to be distributed to outside locations, the discontinuous multi-shipment policy is practically used rather than the continuous policy. Golhar and Sarker (1992) proposed an algorithm to decide optimal lot size for an

* Corresponding author

E-mail: ypchiu@cyut.edu.tw (Y.-S. P. Chiu)

2018 Growing Science Ltd. doi: $10.5267 /$ j.jiiec.2017.11.004 
EMQ-based system by considering discontinuous just-in-time frequent shipments. Their results indicated that the cost function of the problem is convex, and if both fabrication uptime and cycle length are an integer multiple of time interval of deliveries, an optimal delivery size can be derived. Furthermore, they explored the economic impact of setup and ordering costs reduction on the problem.

Sarker and Khan (2001) examined a fabrication-inventory system with a periodic delivery policy. Their objective was to derive optimal batch size that minimizes total system costs. A raw materials procurement policy is used to meet its requirements in lot for in-house fabrication needs. End items are distributed at fixed time interval to meet product demands. Accordingly, a cost function for the proposed fabricationinventory-shipment integrated system was constructed and analyzed. Finally, they proposed a solution procedure to determine the optimal raw materials ordering policy as well as optimal fabrication batch size. Kuhn and Liske (2011) studied a supply and production planning problem which combines the economic lot-sizing and vehicle routing decisions. They established a mathematical model with an exact solution process for a given delivery policy. Through computation of an extensive range of test examples, they obtained analytical results regarding important insight information to the problem that can help determine the most economic solutions. Extra papers relating to diverse characteristics of discontinuous issuing policies in supply chain systems can also be found elsewhere (Hahm \& Yano, 1992; Hill, 1995; Cetinkaya \& Lee, 2000; Abdul-Jalbar et al., 2005; Grunder et al., 2013; Balaji et al., 2015; Cao et al., 2015; Lemma et al., 2015; Aboumasoudi et al., 2016; Chiu et al., 2016c; Qu \& Ji, 2016; Setiawan, 2016).

Furthermore, with the intention of increasing short-term capacity or shortening replenishment cycle length or leveling work/machine loadings to smooth the production planning, adopting overtime option can be an effective strategy. Dixon et al. (1983) examined a manufacturing system with known timevarying demands where no stock-out situation was allowed. The objective was to decide the lot size and refilling timing that minimizes the expected system cost. Flexibility in production includes both regular and overtime with permitted time-varying capacities. They presented a heuristic algorithm and tested on a number of large sets of problems to show the outstanding performance of their proposed heuristic to the problems. Yura (1994) considered a production scheduling problem with the goals of simultaneously meeting workers' preferences in working times as well as meeting due-date constraints. Note that when workloads are heavy, it is not possible to find a solution to satisfy all workers' preferences. Therefore, the scheduling problem aims to minimize total necessary overtime to satisfy workers' preferences. Linear goal programming problems were built and formulated to solve the problem. Numerical example was provided to show how solution process works and what kind of analytical results to the problem can be obtained.

Robinson and Sahin (2001) incorporated overtime option and extra fixed charges for cleanup or inspection into conventional economic production quantity (EPQ) model. Two separate production problems each with mathematical modeling and optimization process were examined by considering separate manufacturing restrictions, setup cost, and availability of overtime capacity. A few experimental sets of problems were used to confirm applicability and excellent performance of the proposed algorithms. Zobolas et al. (2008) intended to improve the master production schedule (MPS) in make-toorder manufacturing systems featuring excessive demand. An algorithm for solving the proposed MPS problem was proposed, which incorporates various constraints such as the production orders guided by tardiness, earliness and overtime penalties. The resource utilization was determined by an intermediate tool - rough cut capacity planning (RCCP) with extra features of positive lead time, overtime option, earliness and tardiness. The proposed model was then solved by a Genetic algorithm. Various benchmarking problems against industrial real data were tested to show that improvements can be gained over the results from conventional RCCP solution process.

Extra papers that explored different characteristics of manufacturing systems with overtime options can also be referred elsewhere (Axsater, 1981; Conley, 1985; Holm \& Kiander, 1993; Schank, 2005; Campbell, 2012; Bazdar et al., 2015; Yilmaz et al., 2016; Renna, 2017). Nevertheless, little attention has 
been paid for the exploration of joint effects of overtime, rework, and discontinuous issuing policy on EMQ model and this paper aims at filling the gap.

\section{Problem, assumption and mathematical modeling}

This study uses mathematical modeling to inspect the effects of overtime option, rework, and discontinuous issuing policy on EMQ model. Description of the problem with mathematical modeling is presented below. First of all, since the overtime option can increase the capacity or expedite manufacturing output rate, we assume $\alpha_{1}$ denotes the adjusted percentage of fabrication rate due to adoption of a particular overtime plan, and the resulting fabrication rate $P_{\mathrm{A}}$ is as follows:

$$
P_{\mathrm{A}}=\left(1+\alpha_{1}\right) P
$$

where $P$ denotes the standard fabrication rate per year. Consequently, manufacturing setup cost $K_{\mathrm{A}}$ and unit cost $C_{\mathrm{A}}$ are higher than standard setup cost $K$ and unit cost $C$. Their relationships are assumed as follows:

$$
\begin{aligned}
& K_{\mathrm{A}}=\left(1+\alpha_{2}\right) K, \\
& C_{\mathrm{A}}=\left(1+\alpha_{3}\right) C,
\end{aligned}
$$

where $\alpha_{2}$ and $\alpha_{3}$ are the respective cost increase proportions. The annual product demand rate is $\lambda$. The manufacturing process is imperfect, assuming an $x$ percentage of defective items may randomly be fabricated, at a rate of $d_{\mathrm{A}}$.

$$
d_{\mathrm{A}}=x P_{\mathrm{A}} .
$$

Maximal on-hand inventories of finished products $H_{1}$ (Fig. 1) in the end of uptime $t_{1 \mathrm{~A}}$ are

$$
H_{1}=\left(P_{\mathrm{A}}-d_{\mathrm{A}}\right) t_{1 \mathrm{~A}} .
$$

All defective items are assumed to be repairable through a rework process in each cycle (see Fig. 1 and Fig. 2), at a rate of $P_{1 \mathrm{~A}}$. The relationship between $P_{1 \mathrm{~A}}$ and standard reworking rate $P_{1}$ is as follows,

$$
P_{1 \mathrm{~A}}=\left(1+\alpha_{1}\right) P_{1} \text {. }
$$

Maximal on-hand inventories of finished products $H$ at the end of rework time $t_{2 \mathrm{~A}}$ are

$$
H=H_{1}+P_{1 \mathrm{~A}} t_{2 \mathrm{~A}} .
$$

At the end of rework process, when the entire production lot is completed, $n$ fixed quantity installments of finished products are delivered to buyer during $t_{3 \mathrm{~A}}$ (Fig. 1). The time interval $t_{\mathrm{nA}}$ between two consecutive distributions is as follows:

$$
t_{\mathrm{nA}}=\frac{t_{3 \mathrm{~A}}}{n}
$$




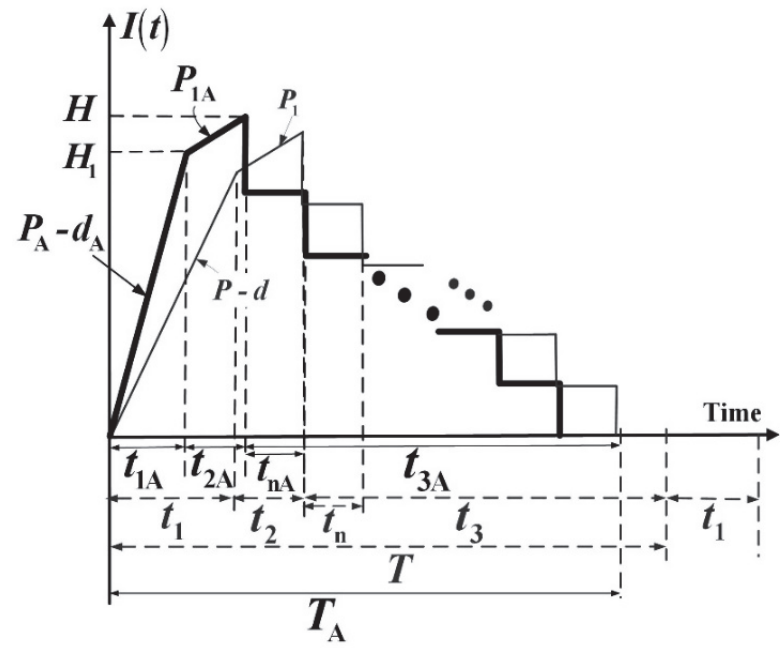

Fig. 1. Inventory level of finished products in any given cycle of the proposed EMQ-based system (in bold lines) compared to that in the classic EMQ model (in thin lines)

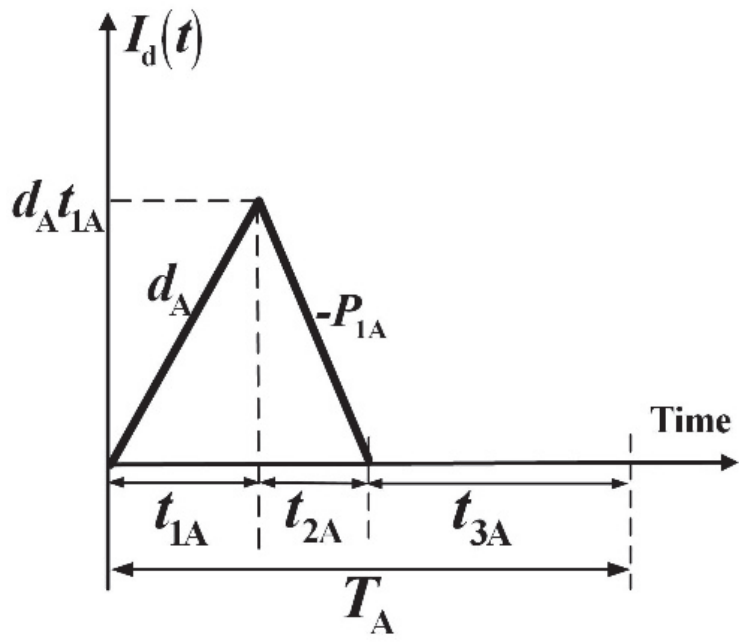

Fig. 2. Inventory level of defective products in the proposed EMQ-based system

Inventory status of finished items during $t_{3 \mathrm{~A}}$ of the proposed EMQ-based system is depicted in Fig. 3.

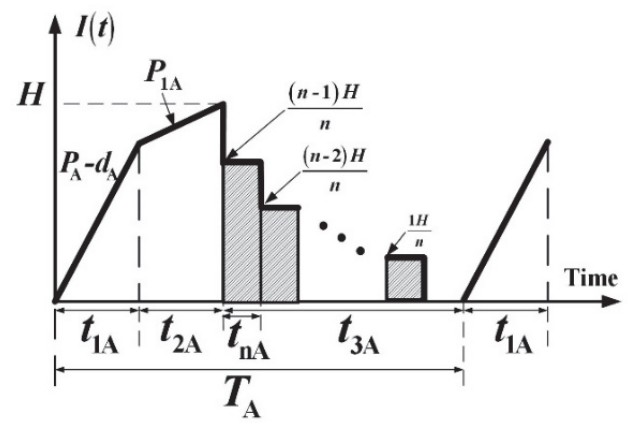

Fig. 3. Inventory level of finished products in $t_{3 \mathrm{~A}}$ of the proposed EMQbased system

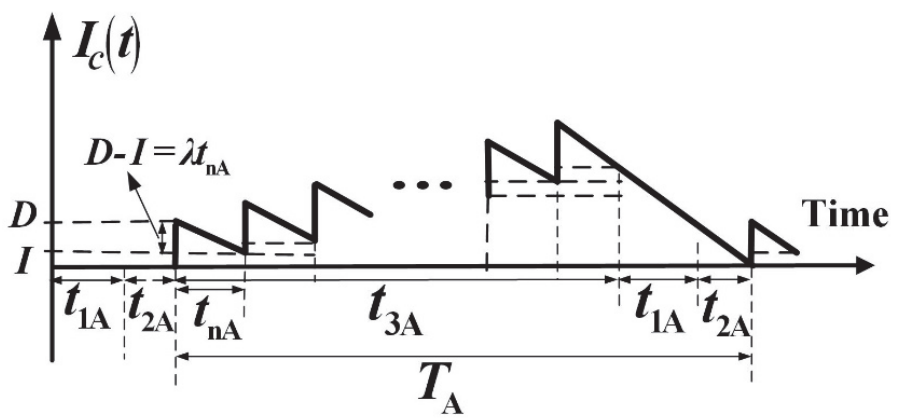

Fig. 4. Status of on-hand stock at the buyer's end

Fig. 4 illustrates the status of on-hand stocks at the buyer's end. Fixed quantity $D$ per shipment and the leftover stocks $I$ (after demand during $t_{\mathrm{nA}}$ is satisfied) are as follows:

$$
\begin{aligned}
& D=\frac{H}{n}, \\
& I=D-\lambda t_{\mathrm{nA}} .
\end{aligned}
$$

Other notations employed in this study are defined as follows:

$Q=$ manufacturing lot size - one of the decision variables,

$T_{\mathrm{A}}=$ manufacturing cycle time,

$n=$ number of shipments per cycle - the other decision variable,

$C_{\mathrm{RA}}=$ unit reworking cost, $C_{\mathrm{RA}}=\left(1+\alpha_{3}\right) C_{\mathrm{R}}$

$h=$ unit holding cost per year,

$h_{1}=$ unit holding cost of reworked item per year,

$K_{1}=$ fixed cost per shipment,

$C_{\mathrm{T}}=$ transportation cost per product,

$h_{2}=$ unit holding cost per year at the buyer's end, 
$T C(Q, n)=$ total cost per cycle of the proposed EMQ-based system,

$\mathrm{E}\left[T_{\mathrm{A}}\right]=$ the expected cycle time of the proposed EMQ-based system,

$\mathrm{E}[\operatorname{TCU}(Q, n)]=$ the expected total system cost per unit time of the proposed EMQ-based system,

$I(t)=$ level of on-hand inventories at time $t$,

$I_{\mathrm{d}}(t)=$ level of on-hand defective items at time $t$,

$I_{\mathrm{c}}(t)=$ level of on-hand inventories at buyer end at time $t$,

$t_{1}=$ uptime of the classic EMQ model,

$d=$ production rate of defective items in the classic EMQ model,

$t_{2}=$ rework time of the classic EMQ model,

$t_{3}=$ delivery time of the classic EMQ model,

$T=$ cycle time of the classic EMQ model,

$C_{\mathrm{R}}=$ unit reworking cost of the classic EMQ model,

$t_{\mathrm{n}}=$ interval of time between two consecutive shipments in the classic EMQ model.

The following manufacturing lot-size, uptime, reworking time, delivery time, and manufacturing cycle time can be obtained accordingly (see Fig. 1):

$$
\begin{aligned}
& Q=P_{\mathrm{A}} t_{1 \mathrm{~A}} \\
& t_{1 \mathrm{~A}}=\frac{Q}{P_{\mathrm{A}}}=\frac{Q}{\left(1+\alpha_{1}\right) P}=\frac{H_{1}}{P_{\mathrm{A}}-d_{\mathrm{A}}}=\frac{H_{1}}{\left[\left(1+\alpha_{1}\right) P\right](1-x)} \\
& t_{2 \mathrm{~A}}=\frac{x Q}{P_{1 \mathrm{~A}}}=\frac{x Q}{\left(1+\alpha_{1}\right) P_{1}} \\
& t_{3 \mathrm{~A}}=T_{\mathrm{A}}-t_{1 \mathrm{~A}}-t_{2 \mathrm{~A}}=\frac{Q}{\lambda}-\frac{Q}{\left(1+\alpha_{1}\right) P}-\frac{x Q}{\left(1+\alpha_{1}\right) P_{1}} \\
& T_{\mathrm{A}}=t_{1 \mathrm{~A}}+t_{2 \mathrm{~A}}+t_{3 \mathrm{~A}}=\frac{Q}{\lambda}
\end{aligned}
$$

Total defective items produced at the end of uptime are (Fig. 2):

$$
d_{\mathrm{A}} t_{1 \mathrm{~A}}=x Q
$$

During the delivery time), total inventories (Fig. 3) are

$$
\left(\frac{1}{n^{2}}\right)\left(\sum_{i=1}^{n-1} i\right) H t_{3 \mathrm{~A}}=\left(\frac{1}{n^{2}}\right)\left[\frac{n(n-1)}{2}\right] H t_{3 \mathrm{~A}}=\left(\frac{n-1}{2 n}\right) H t_{3 \mathrm{~A}}
$$

Observing Fig. 4 and from the relevant definitions of system parameters (Eqs. (8-10)), we can obtain total inventories at buyer's end in a replenishment cycle as follows (Chiu et al., 2015):

$$
n\left(D-\frac{\lambda t_{n \mathrm{~A}}}{2}\right) t_{n \mathrm{~A}}+\frac{n(n-1)}{2} I t_{n \mathrm{~A}}+\frac{n I}{2}\left(t_{1 \mathrm{~A}}+t_{2 \mathrm{~A}}\right)=\frac{1}{2}\left[\frac{H t_{3 \mathrm{~A}}}{n}+T_{\mathrm{A}}\left(H-\lambda t_{3 \mathrm{~A}}\right)\right] .
$$

Total cost per cycle of the proposed EMQ-based system $T C(Q, n)$ comprises manufacturing setup cost, variable production cost, rework cost, fixed and variable transportation costs, inventory holding costs for perfect quality products in setup, rework, and delivery time, holding cost for nonconforming items in rework time, and stock holding cost at the customer side. Hence, $\operatorname{TC}(Q, n)$ is as follows: 


$$
\begin{aligned}
T C(Q, n) & =K_{\mathrm{A}}+C_{\mathrm{A}} Q+C_{\mathrm{RA}}(x Q)+n K_{1}+C_{T} Q+h\left[\frac{H_{1}+d_{\mathrm{A}} t_{1 \mathrm{~A}}}{2}\left(t_{1 \mathrm{~A}}\right)+\frac{H_{1}+H}{2}\left(t_{2 \mathrm{~A}}\right)\right] \\
& +h\left(\frac{n-1}{2 n}\right) H t_{3 \mathrm{~A}}+h_{1} \frac{P_{1 \mathrm{~A}} t_{2 \mathrm{~A}}}{2}\left(t_{2 \mathrm{~A}}\right)+\frac{h_{2}}{2}\left[\frac{H t_{3 A}}{n}+T_{A}\left(H-\lambda t_{3 A}\right)\right] .
\end{aligned}
$$

Replacing $K_{\mathrm{A}}, C_{\mathrm{A}}, C_{\mathrm{RA}}, d_{\mathrm{A}}, P_{\mathrm{A}}$, and $P_{1 \mathrm{~A}}$ with their corresponding standard variables $(K, C, C$ R, $d, P$, and $\left.P_{1}\right), T C(Q, n)$ is computed as follows,

$$
\begin{aligned}
T C(Q, n) & =\left(1+\alpha_{2}\right) K+\left(1+\alpha_{3}\right) C Q+\left(1+\alpha_{3}\right) C_{\mathrm{R}} x Q+n K_{1}+C_{T} Q \\
& +h\left[\frac{H_{1}+x\left[\left(1+\alpha_{1}\right) P\right] t_{1 \mathrm{~A}}}{2}\left(t_{1 \mathrm{~A}}\right)+\frac{H_{1}+H}{2}\left(t_{2 \mathrm{~A}}\right)\right]+h\left(\frac{n-1}{2 n}\right) H t_{3 \mathrm{~A}} \\
& +h_{1} \frac{\left[\left(1+\alpha_{1}\right) P_{1}\right] t_{2 \mathrm{~A}}}{2}\left(t_{2 \mathrm{~A}}\right)+\frac{h_{2}}{2}\left[\frac{H t_{3 A}}{n}+T_{A}\left(H-\lambda t_{3 A}\right)\right] .
\end{aligned}
$$

By substituting Eqs. (5-7) and Eq. (13) to Eq. (15) in $\operatorname{TCU}(Q, n)$, and also by applying the expected values of $x$ to deal with its randomness, and with extra derivations, $\mathrm{E}[T C U(Q, n)]$ can be obtained as follows:

$$
\begin{aligned}
E[T C U(Q, n)]= & \frac{E[T C(Q, n)]}{E\left[T_{\mathrm{A}}\right]}=\lambda\left[\left(1+\alpha_{3}\right) C+\left(1+\alpha_{3}\right) C_{R} E[x]\right]+\frac{\left[\left(1+\alpha_{2}\right) K\right] \lambda}{Q} \\
& +\frac{n K_{1} \lambda}{Q}+C_{T} \lambda+\frac{h Q}{2}+\frac{\lambda Q\left(h_{1}-h\right) E[x]^{2}}{2\left(1+\alpha_{1}\right) P_{1}}+\frac{h Q \lambda E[x]}{2\left(1+\alpha_{1}\right) P_{1}} \\
& +\left(h_{2}-h\right) Q\left(\frac{1}{2 n}\right)\left\{1-\frac{\lambda}{\left(1+\alpha_{1}\right)}\left[\frac{1}{P}+\frac{E[x]}{P_{1}}\right]\right\}+\frac{h_{2} Q}{2} \frac{\lambda}{\left(1+\alpha_{1}\right)}\left[\frac{1}{P}+\frac{E[x]}{P_{1}}\right] .
\end{aligned}
$$

\section{Determining manufacturing lot size and shipments per cycle}

First, we verify the following Hessian matrix equations (Rardin, 1998) and make certain that $E[T C U(Q$, $n)]$ is convex (see Appendix for details):

$$
\left[\begin{array}{ll}
Q & n
\end{array}\right] \cdot\left(\begin{array}{ll}
\frac{\partial^{2} E[T C U(Q, n)]}{\partial Q^{2}} & \frac{\partial^{2} E[T C U(Q, n)]}{\partial Q \partial n} \\
\frac{\partial^{2} E[T C U(Q, n)]}{\partial Q \partial n} & \frac{\partial^{2} E[T C U(Q, n)]}{\partial n^{2}}
\end{array}\right) \cdot\left[\begin{array}{l}
Q \\
n
\end{array}\right]=\frac{2\left[\left(1+\alpha_{2}\right) K\right] \lambda}{Q}>0 .
$$

Then, by setting the first and the second partial derivatives of $E[T C U(Q, n)]$ equal to 0 and solving the following linear system (from Eqs. (A-1) and (A-3)):

$$
\begin{aligned}
\frac{\partial E[T C U(Q, n)]}{\partial Q}= & -\frac{\left[\left(1+\alpha_{2}\right) K\right] \lambda}{Q^{2}}-\frac{n K_{1} \lambda}{Q^{2}}+\frac{h}{2}+\frac{\lambda\left(h_{1}-h\right) E[x]^{2}}{2\left(1+\alpha_{1}\right) P_{1}}+\frac{h \lambda E[x]}{2\left(1+\alpha_{1}\right) P_{1}} \\
& +\left(h_{2}-h\right)\left(\frac{1}{2 n}\right)\left\{1-\frac{\lambda}{\left(1+\alpha_{1}\right)}\left[\frac{1}{P}+\frac{E[x]}{P_{1}}\right]\right\}+\frac{h_{2}}{2} \frac{\lambda}{\left(1+\alpha_{1}\right)}\left[\frac{1}{P}+\frac{E[x]}{P_{1}}\right]=0, \\
\frac{\partial E[T C U(Q, n)]}{\partial n}= & \frac{K_{1} \lambda}{Q}-\left(h_{2}-h\right) Q\left(\frac{1}{2 n^{2}}\right)\left\{1-\frac{\lambda}{\left(1+\alpha_{1}\right)}\left[\frac{1}{P}+\frac{E[x]}{P_{1}}\right]\right\}=0,
\end{aligned}
$$

and with extra derivatives of the aforementioned linear system, we may find the optimal manufacturing lot size and the number of shipments per cycle as follows: 


$$
Q^{*}={\sqrt{h+\frac{h \lambda E[x]}{\left(1+\alpha_{1}\right) P_{1}}+\frac{\lambda\left[h_{1}-h\right] E[x]^{2}}{\left(1+\alpha_{1}\right) P_{1}}+\frac{h_{2} \lambda}{\left(1+\alpha_{1}\right)}\left[\frac{1}{P}+\frac{E[x]}{P_{1}}\right]+\frac{\left(h_{2}-h\right)}{n}\left\{1-\frac{\lambda}{\left(1+\alpha_{1}\right)}\left[\frac{1}{P}+\frac{E[x]}{P_{1}}\right]\right.}}_{,}^{,}
$$

and

$$
n^{*}=\sqrt{\frac{\left(1+\alpha_{2}\right) K\left(h_{2}-h\right) \delta}{K_{1}\left\{h+\frac{h \lambda E[x]}{\left(1+\alpha_{1}\right) P_{1}}+\frac{\lambda\left(h_{1}-h\right) E[x]^{2}}{\left(1+\alpha_{1}\right) P_{1}}+\frac{h_{2} \lambda}{\left(1+\alpha_{1}\right)}\left[\frac{1}{P}+\frac{E[x]}{P_{1}}\right]\right\}}},
$$

where $\delta=\left\{1-\frac{\lambda}{\left(1+\alpha_{1}\right)}\left[\frac{1}{P}+\frac{E[x]}{P_{1}}\right]\right\}$

\section{Numerical example with sensitivity analyses}

A numerical example with sensitivity analyses is provided below to demonstrate the applicability of the proposed method. Assuming that the following variables are in an economic manufacturing quantity model and by considering overtime option, rework, and discontinuous product issuing policy:
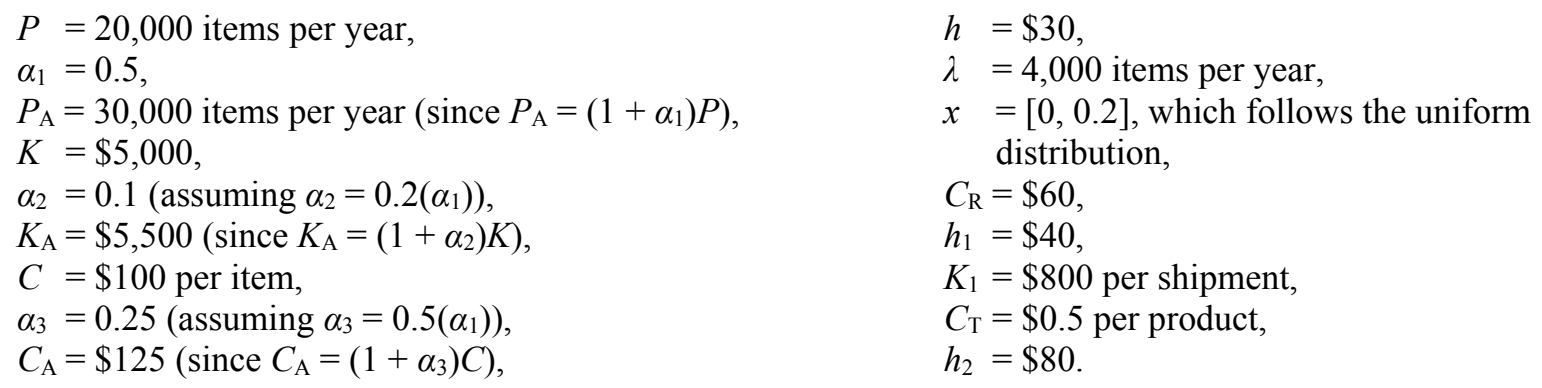

\subsection{Optimality and rework issues}

Applying Eqs. (25-26), and Eq. (21), the following optimal replenishment lot size, shipments per cycle, and the expected system cost can be found: $Q^{*}=1,025, n^{*}=3$, and $E\left[T C U\left(Q^{*}, n^{*}\right)\right]=\$ 593,652$. Further analyses illustrate the behavior of $E[T C U(Q, n)]$ with respective to $Q$ (Fig. 5), and effect of nonconforming rate on different system cost components of $E[T C U(Q, n)]$ in the proposed EMQ-based system (Fig. 6).

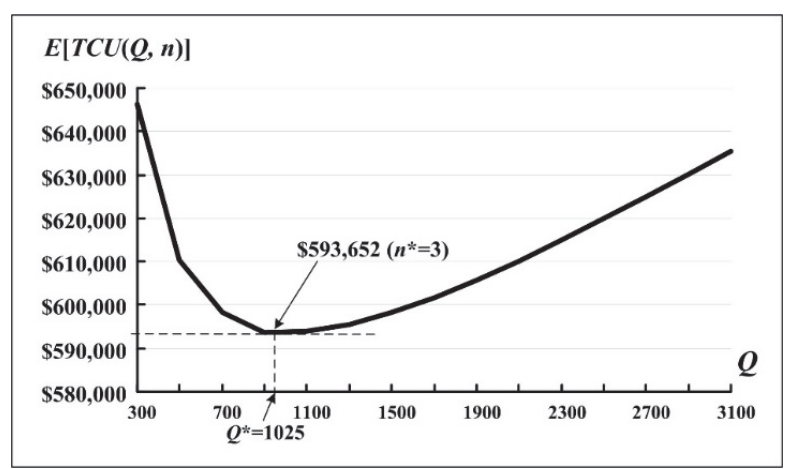

Fig. 5. Behavior of $E[T C U(Q, n)]$ with respective to $Q$ in the proposed EMQ-based system

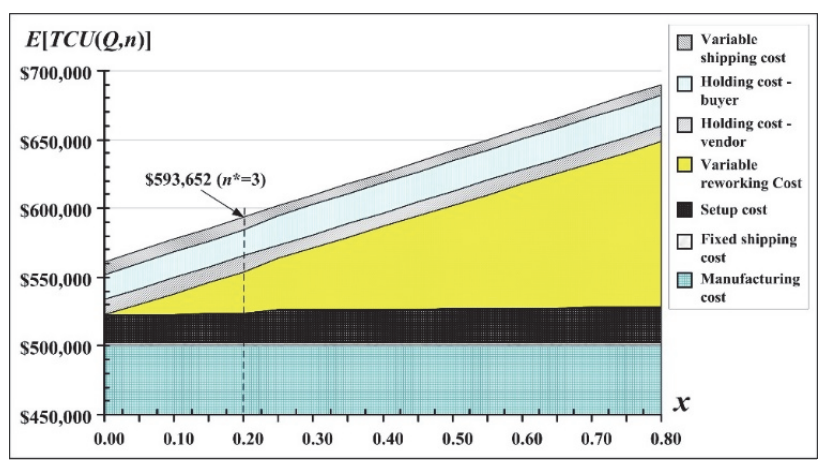

Fig. 6. Effect of nonconforming rate on different system cost components of $E[T C U(Q, n)]$ 
From Fig. 6, it is noted that as nonconforming rate $x$ goes up, variable reworking cost increases significantly, and certainly, so does the expected total system cost $E[T C U(Q, n)]$. The joint effects of replenishment lot size $Q$ and number of shipments $n$ per cycle on the expected total system costs $E[T C U(Q, n)]$ are depicted in Fig. 7. It can be seen that the optimal operating policy $\left(Q^{*}=1,025, n^{*}=\right.$ $3)$ is reconfirmed.

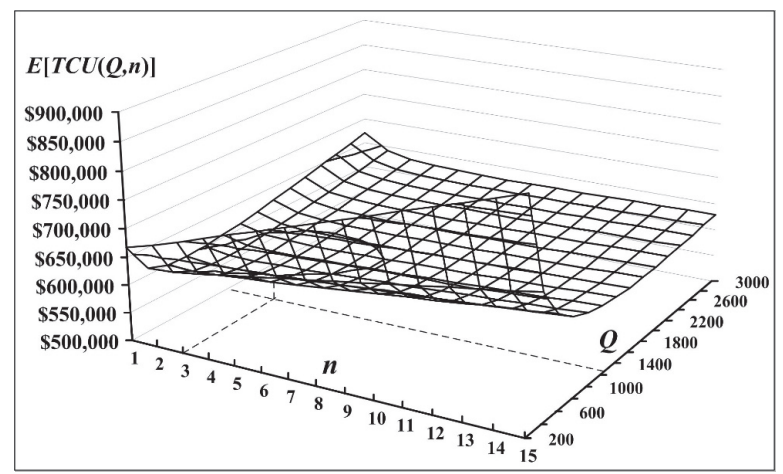

Fig. 7. Joint effects of replenishment lot size and shipments per cycle on the expected total system costs $E[T C U(Q, n)]$

\subsection{Joint effects from overtime relating factors and rework}

With further investigation on the effects of variations in $\alpha_{i}$ (i.e., those parameters associated with overtime option) on the proposed system, certain important information is revealed (as shown in Appendix B: Table B-1 and Table B-2). Joint effects of variations in adjusted factor $\alpha_{1}$ and random nonconforming rate $x$ on the expected total system cost are shown in Fig. 8. It is noted that as $\alpha_{1}$ increases (i.e., more overtime are put into operation), expected total system cost $E[T C U(Q, n)]$ goes up notably; as nonconforming rate $x$ goes higher, $E[T C U(Q, n)]$ rises accordingly. From analytical results shown in Table B-1, the impact of overtime output adjusted rate $\alpha_{1}$ on the optimal replenishment lot size $Q^{*}$ and shipments per cycle $n^{*}$ is exposed as illustrated in Fig. 9.

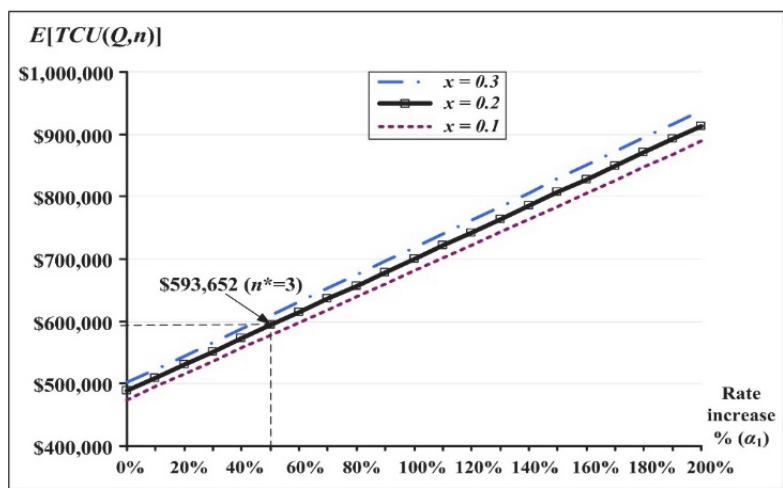

Fig. 8. Joint effects of adjusted factor $\alpha_{1}$ and nonconforming rate $x$ on $E[T C U(Q, n)]$

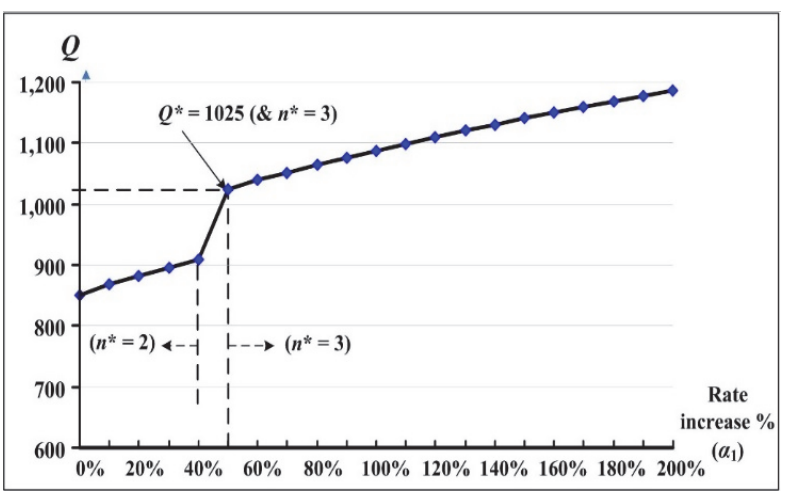

Fig. 9. Impact of variations in $\alpha_{1}$ on the optimal replenishment lot size and shipments per cycle

It indicates that as $\alpha_{1}$ increases (i.e., more overtime are put into operation), $Q^{*}$ goes up and $n *$ increases from 2 to 3 at $\alpha_{1}=50 \%$ and up. The analytical results (from Table B-1, Appendix B) also point out the effect of overtime unit cost increase rate $\alpha_{3}$ on the expected total system cost $E[T C U(Q, n)]$ (Fig. 10). For instance, at $\alpha_{3}=25 \%$ (i.e., corresponding $\alpha_{1}=50 \%$ ), $E[T C U(Q, n)]$ increases $21.64 \%$ as compared to that in the same system operation without overtime option. As $\alpha_{3}$ goes higher, the expected total system cost increases significantly. 


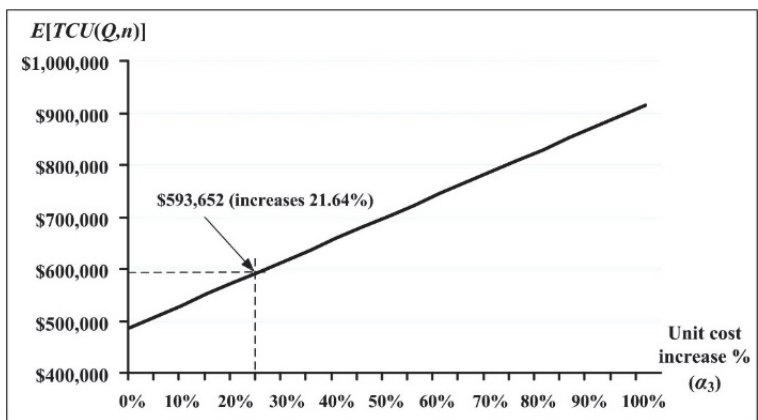

Fig. 10. Effect of overtime unit cost increase rate $\alpha_{3}$ on the expected total system cost

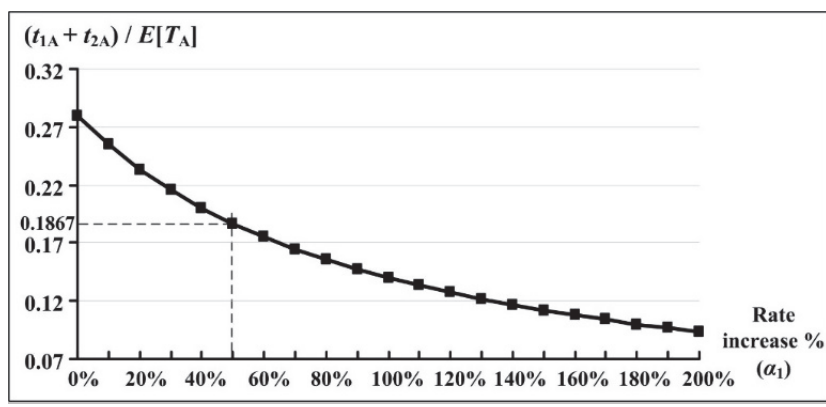

Fig. 11. The impact of variations in overtime output adjusted rate $\alpha_{1}$ on machine utilization

Further, from the analytical results shown in Table B-2, the impact of variations in overtime output adjusted rate $\alpha_{1}$ on machine utilization is revealed (Fig. 11). It can be seen that at $\alpha_{1}=50 \%$, machine utilization (i.e., the ratio of (the sum of uptime $t_{1 \mathrm{~A}}$ and rework time $t_{2 \mathrm{~A}}$ ) over the expected cycle length $\left.E\left[T_{\mathrm{A}}\right]\right)$ drops $18.67 \%$; and as $\alpha_{1}$ goes up, machine utilization keep on declining accordingly.

\section{Conclusions}

An EMQ-based model incorporating an overtime option, rework, and a discontinuous issuing policy for end items has been developed in this study. Such a decision-support model not only provides the optimal replenishment lot size and number of shipments per cycle (see Figs. 5 and 7), but also allows production managers to identify the individual and combined effects of various important system factors on the system's decision variables, expected total cost per unit time, and machine utilization. These critical factors include random defective rate (see Fig. 8), output-adjusted rate due to overtime (see Figs. 9 and 11), and unit cost-increase rate due to overtime (see Fig. 10). Without such an in-depth study, a variety of information related to managerial decision making remains ignored.

\section{Acknowledgements}

This study was sponsored by Ministry of Science and Technology of Taiwan (MOST) under grant no. MOST-104-2410-H-324-008-MY2.

\section{References}

Abdul-Jalbar, B., Gutiérrez, J., \& Sicilia, J. (2005). Integer-ratio policies for distribution/ inventory systems. International Journal of Production Economics, 93-94, 407-415.

Aboumasoudi, A.S., Mirzamohammadi, S., Makui, A., \& Tamosaitiene, J. (2016). Development of networkranking model to create the best production line value chain: A case study in Textile industry. Economic Computation and Economic Cybernetics Studies and Research, 50(1), 215-234.

Axsater, S. (1981). Economic order quantities and variations in production load: Interpretation of capacity costs as costs for regular capacity and overtime. International Journal of Production Research, 19(4), 439-440.

Balaji, M., Velmurugan, V., \& Subashree, C. (2015). TADS: An assessment methodology for agile supply chains. Journal of Applied Research and Technology 13(5), 504-509.

Bazdar, A., Kazemzadeh, R.B., \& Niaki, S.T.A. (2015). Variation source identification of multistage manufacturing processes through discriminant analysis and stream of variation methodology: A case study in automotive industry. Journal of Engineering Research, 3(2), 96-108.

Boone, T., Ganeshan, R., Guo, Y., \& Ord, J.K. (2000). The impact of imperfect processes on production run times. Decision Sciences, 31(4), 773-785.

Campbell, G.M. (2012). On-call overtime for service workforce scheduling when demand is uncertain. Decision Sciences, 43(5), 817-850.

Cao, J., Chen, Y., \& Zhou, G. (2015). A novel statistical prediction technique based on the dynamic relationship identification algorithm to forecast supply chain demand. Economic Computation and Economic Cybernetics Studies and Research, 49(1), 5-22.

Cetinkaya, S., \& Lee, C.Y. (2000). Stock replenishment and shipment scheduling for vendor managed inventory systems. Management Science, 46 (2), 217-232.

Chiu, Y.-S.P., Wu, M.-F., Chiu, S.W., \& Chang, H.-H. (2015). A simplified approach to the multi-item economic production quantity model with scrap, rework, and multi-delivery. Journal of Applied Research and 
Technology, 13(4), 472-476.

Chiu, S.W., Chen, S.-W., Chiu, Y.-S.P., \& Li, T.-W. (2016a). Producer-retailer integrated EMQ system with machine breakdown, rework failures, and a discontinuous inventory issuing policy. SpringerPlus, 5(1), art. no. 339.

Chiu, Y-S.P., Kuo, J-S., Chiu, S.W., \& Hsieh, Y-T. (2016b). Effect of delayed differentiation on a multi-product vendor-buyer integrated inventory system with rework. Advances in Production Engineering \& Management 11(4), 333-344.

Chiu, Y-S.P., Liang, G-M., \& Chiu, S.W. (2016c). Solving a fabrication lot-size and shipping frequency problem with an outsourcing policy and random scrap. Mathematical and Computational Applications, 21(4), art. no. 45.

Conley, W. (1985). Production scheduling with overtime considerations. International Journal on Policy and Information, 9(1), 149-157.

Dhaiban, A.K., Baten, M.A., \& Aziz, N. (2017). A manufacturing-inventory control model with defective and deteriorating items. Far East Journal of Mathematical Sciences, 101(8), 1691-1709.

Dixon, P.S., Elder, M.D., Rand, G.K., \& Silver, E.A. (1983) A heuristic algorithm for determining lot sizes of an item subject to regular and overtime production capacities. Journal of Operations Management, 3(3), 121130.

Golhar, D., \& Sarker, B. (1992). Economic manufacturing quantity in a just-in-time delivery system. International Journal of Production Research, 30(5), 961-972.

Grunder, O., Wang, D., \& El Moudni, A. (2013). Production scheduling problem with delivery considerations in a mono-product supply chain environment to minimise the total joint cost. European Journal of Industrial Engineering, 7 (5), 615-634.

Hahm, J., \& Yano, C.A. (1992). The economic lot and delivery scheduling problem: The single item case. International Journal of Production Economics, 28, 235-252.

Henig, M., \& Gerchak, Y. (1990). Structure of periodic review policies in the presence of random yield. Operations Research, 38(4), 634-643.

Hill, R.M. (1995). On an optimal batch size for a production system operating under a fixed-quantity, periodic delivery policy. Journal of the Operational Research Society, 46(2), 271-273.

Holm, P., \& Kiander, J. (1993). The effects of work sharing on employment and overtime in Finnish manufacturing 1960-87: Comparison of three alternative models. Applied Economics, 25(6), 801-810.

Inderfurth, K., Janiak, A., Kovalyov, M.Y., \& Werner, F. (2006). Batching work and rework processes with limited deterioration of reworkables. Computers and Operations Research, 33(6), 1595-1605.

Jindal, P., \& Solanki, A. (2016). Integrated supply chain inventory model with quality improvement involving controllable lead time and backorder price discount. International Journal of Industrial Engineering Computations, 7(3), 463-480.

Jawla, P., \& Singh, S.R. (2016). Multi-item economic production quantity model for imperfect items with multiple production setups and rework under the effect of preservation technology and learning environment. International Journal of Industrial Engineering Computations, 7(4), 703-716.

Khanna, A., Kishore, A., \& Jaggi, C.K. (2017). Strategic production modeling for defective items with imperfect inspection process, rework, and sales return under two-level trade credit. International Journal of Industrial Engineering Computations, 8(1), 85-118.

Kim, K.R., Sung, C.O., Kwon, T.J., Lee, J., \& Robboy, S.J. (2015). Defective pericyte recruitment of villous stromal vessels as the possible etiologic cause of hydropic change in complete hydatidiform mole. PLoS ONE, 10(4), art. no. e0122266.

Koley E, Verma K, \& Ghosh S. (2015). An improved fault detection classification and location scheme based on wavelet transform and artificial neural network for six phase transmission line using single end data only. SpringerPlus, 4(1), art. no. 551.

Koren, R., \& Palčič, I. (2015). The impact of technical and organisational innovation concepts on product characteristics. Advances in Production Engineering \& Management, 10(1), 27-39.

Kuhn, H., \& Liske, T. (2011). Simultaneous supply and production planning. International Journal of Production Research, 49 (13), 3795-3813.

Lemma, H.R., Singh, R., \& Kaur, N. (2015). Determinants of supply chain coordination of milk and dairy industries in Ethiopia: a case of Addis Ababa and its surroundings. SpringerPlus, 4(1), art. no. 498.

Maddah, B., Moussawi, L., \& Jaber, M.Y. (2010). Lot sizing with a Markov production process and imperfect items scrapped. International Journal of Production Economics, 124 (2), 340-347.

Mak, K.L. (1985). Inventory control of defective products when the demand is partially captive. International Journal of Production Research, 23(3), 533-542.

Qu, S., \& Ji, Y. (2016) The worst-case weighted multi-objective game with an application to supply chain competitions. PLoS ONE, 11(1), art. no. e0147341.

Rardin, R.L. (1998). Optimization in Operations Research, Prentice-Hall, New Jersey, 739-741.

Renna, P. (2017). Allocation improvement policies to reduce process time based on workload evaluation in job shop manufacturing systems. International Journal of Industrial Engineering Computations, 8(3), 373-384.

Robinson Jr., E.P., \& Sahin, F. (2001). Economic production lot sizing with periodic costs and overtime. Decision 
Sciences, 32(3), 423-451.

Sarker, R.A., \& Khan, L.R. (2001). An optimal batch size under a periodic delivery policy. International Journal of Systems Science, 32(9), 1089-1099.

Schank, T. (2005). Are overtime plants more efficient than standard-time plants? A stochastic production frontier analysis using the IAB Establishment Panel. Empirical Economics, 30(3), 693-710.

Setiawan, R. (2016). A game theory approach in vendor-buyer probabilistic inventory system with imperfect quality, inspection error, minimum service level constraint and partial backordering. Far East Journal of Mathematical Sciences, 100(10), 1695-1704.

Taft, E.W. (1918). The most economical production lot. Iron Age, 101, 1410-1412.

Taleizadeh, A.A., Wee, H-M., \& Sadjadi, S.J. (2010). Multi-product production quantity model with repair failure and partial backordering. Computers and Industrial Engineering, 59, 45-54.

Yilmaz, O.F., Cevikcan, E., \& Durmusoglu, M.B. (2016). Scheduling batches in multi hybrid cell manufacturing system considering worker resources: A case study from pipeline industry. Advances in Production Engineering and Management, 11(3), 192-206.

Yum, B.J. \& McDowell, E.D. (1987). Optimal inspection policies in a serial production system including scrap, rework and repair: An MILP approach. International Journal of Production Research, 25(10), 1451-1464.

Yura, K. (1994) Production scheduling to satisfy worker's preferences for days off and overtime under due-date constraints. International Journal of Production Economics, 33(1-3), 265-270.

Zargar, A.M. (1995). Effect of rework strategies on cycle time. Computers and Industrial Engineering, 29(14), 239-243.

Zhang, D., Zhang, Y., \& Yu, M. (2016). A machining process oriented modeling approach for reliability optimization of failure-prone manufacturing systems. Journal of Engineering Research, 4(3), 128-143.

Zobolas, G.I., Tarantilis, C.D., \& Ioannou, G. (2008). Extending capacity planning by positive lead times and optional overtime, earliness and tardiness for effective master production scheduling. International Journal of Production Research, 46(12), 3359-3386.

\section{Appendix A}

From Eq. (21), derivations of Hessian matrix equations (Rardin, 1998) are presented as follows:

$$
\begin{aligned}
& \frac{\partial E[T C U(Q, n)]}{\partial Q}=-\frac{\left[\left(1+\alpha_{2}\right) K\right] \lambda}{Q^{2}}-\frac{n K_{1} \lambda}{Q^{2}}+\frac{h}{2}+\frac{\lambda\left(h_{1}-h\right) E[x]^{2}}{2\left(1+\alpha_{1}\right) P_{1}}+\frac{h \lambda E[x]}{2\left(1+\alpha_{1}\right) P_{1}} \\
& +\left(h_{2}-h\right)\left(\frac{1}{2 n}\right)\left\{1-\frac{\lambda}{\left(1+\alpha_{1}\right)}\left[\frac{1}{P}+\frac{E[x]}{P_{1}}\right]\right\}+\frac{h_{2}}{2} \frac{\lambda}{\left(1+\alpha_{1}\right)}\left[\frac{1}{P}+\frac{E[x]}{P_{1}}\right], \\
& \frac{\partial^{2} E[T C U(Q, n)]}{\partial Q^{2}}=\frac{2\left[\left(1+\alpha_{2}\right) K\right] \lambda}{Q^{3}}+\frac{2 n K_{1} \lambda}{Q^{3}}, \\
& \frac{\partial E[T C U(Q, n)]}{\partial n}=\frac{K_{1} \lambda}{Q}-\left(h_{2}-h\right) Q\left(\frac{1}{2 n^{2}}\right)\left\{1-\frac{\lambda}{\left(1+\alpha_{1}\right)}\left[\frac{1}{P}+\frac{E[x]}{P_{1}}\right]\right\}, \\
& \frac{\partial^{2} E[T C U(Q, n)]}{\partial n^{2}}=\left(h_{2}-h\right) Q\left(\frac{1}{n^{3}}\right)\left\{1-\frac{\lambda}{\left(1+\alpha_{1}\right)}\left[\frac{1}{P}+\frac{E[x]}{P_{1}}\right]\right\}, \\
& \frac{\partial E[T C U(Q, n)]}{\partial Q \partial n}=-\frac{K_{1} \lambda}{Q^{2}}-\left(h_{2}-h\right)\left(\frac{1}{2 n^{2}}\right)\left\{1-\frac{\lambda}{\left(1+\alpha_{1}\right)}\left[\frac{1}{P}+\frac{E[x]}{P_{1}}\right]\right\} .
\end{aligned}
$$

With extra derivations, the resulting Hessian matrix equations are as follows:

$$
\left[\begin{array}{ll}
Q & n
\end{array}\right] \cdot\left(\begin{array}{ll}
\frac{\partial^{2} E[T C U(Q, n)]}{\partial Q^{2}} & \frac{\partial^{2} E[T C U(Q, n)]}{\partial Q \partial n} \\
\frac{\partial^{2} E[T C U(Q, n)]}{\partial Q \partial n} & \frac{\partial^{2} E[T C U(Q, n)]}{\partial n^{2}}
\end{array}\right) \cdot\left[\begin{array}{l}
Q \\
n
\end{array}\right]=\frac{2\left[\left(1+\alpha_{2}\right) K\right] \lambda}{Q}>0
$$

Since $\alpha_{2}, K, \lambda$, and $Q$ are all positive, thus, Eq. (A-6) is positive. So, $E[T C U(Q, n)]$ is strictly convex function for all $Q$ and $n$ different from zero. 


\section{Appendix B}

\section{Table B-1}

Joint effects of variations in adjusted factors $\alpha_{1}$ and $\alpha_{3}$ on the optimal replenishment lot size and shipments, the expected total system cost, and system cost increase \%

\begin{tabular}{|c|c|c|c|c|c|}
\hline$\alpha_{1} \%$ & $\alpha_{3} \%$ & $Q^{*}$ & $n^{*}$ & $E[T C U(Q)]$ & $\%$ of cost increases \\
\hline $0 \%$ & $0 \%$ & 865 & 2 & $\$ 488,041$ & - \\
\hline $10 \%$ & $5 \%$ & 878 & 2 & $\$ 509,004$ & $4.30 \%$ \\
\hline $20 \%$ & $10 \%$ & 890 & 2 & $\$ 530,067$ & $8.61 \%$ \\
\hline $30 \%$ & $15 \%$ & 901 & 2 & $\$ 551,206$ & $12.94 \%$ \\
\hline $40 \%$ & $20 \%$ & 911 & 2 & $\$ 572,405$ & $17.29 \%$ \\
\hline $50 \%$ & $25 \%$ & 1,025 & 3 & $\$ 593,652$ & $21.64 \%$ \\
\hline $60 \%$ & $30 \%$ & 1,036 & 3 & $\$ 614,805$ & $25.97 \%$ \\
\hline $70 \%$ & $35 \%$ & 1,047 & 3 & $\$ 636,000$ & $30.32 \%$ \\
\hline $80 \%$ & $40 \%$ & 1,057 & 3 & $\$ 657,229$ & $34.67 \%$ \\
\hline $90 \%$ & $45 \%$ & 1,067 & 3 & $\$ 678,488$ & $39.02 \%$ \\
\hline $100 \%$ & $50 \%$ & 1,076 & 3 & $\$ 699,771$ & $43.38 \%$ \\
\hline $110 \%$ & $55 \%$ & 1,085 & 3 & $\$ 721,075$ & $47.75 \%$ \\
\hline $120 \%$ & $60 \%$ & 1,094 & 3 & $\$ 742,396$ & $52.12 \%$ \\
\hline $130 \%$ & $65 \%$ & 1,103 & 3 & $\$ 763,734$ & $56.49 \%$ \\
\hline $140 \%$ & $70 \%$ & 1,112 & 3 & $\$ 785,084$ & $60.86 \%$ \\
\hline $150 \%$ & $75 \%$ & 1,120 & 3 & $\$ 806,447$ & $65.24 \%$ \\
\hline $160 \%$ & $80 \%$ & 1,128 & 3 & $\$ 827,819$ & $69.62 \%$ \\
\hline $170 \%$ & $85 \%$ & 1,136 & 3 & $\$ 849,201$ & $74.00 \%$ \\
\hline $180 \%$ & $90 \%$ & 1,144 & 3 & $\$ 870,590$ & $78.38 \%$ \\
\hline $190 \%$ & $95 \%$ & 1,152 & 3 & $\$ 891,986$ & $82.77 \%$ \\
\hline $200 \%$ & $100 \%$ & 1,160 & 3 & $\$ 913,389$ & $87.15 \%$ \\
\hline
\end{tabular}

\section{Table B-2}

Effect of variations in adjusted factor $\alpha_{1}$ on fabrication uptime, reworking time, expected cycle length, machine utilization and its decrease $\%$

\begin{tabular}{|c|c|c|c|c|c|}
\hline $\begin{array}{l}\alpha_{1} \\
\%\end{array}$ & $\begin{array}{l}\text { Uptime } \\
\left(t_{1 \mathrm{~A}}\right)\end{array}$ & $\begin{array}{l}\text { Reworking } \\
\text { time }\left(t_{2 \mathrm{~A}}\right)\end{array}$ & $E\left[T_{\mathrm{A}}\right]$ & $\begin{array}{c}\text { Machine } \\
\text { utilization } \\
\left(t_{1 \mathrm{~A}}+t_{2 \mathrm{~A}}\right) / E\left[T_{\mathrm{A}}\right]\end{array}$ & $\begin{array}{c}\% \text { utilization } \\
\text { decreases }\end{array}$ \\
\hline $0 \%$ & 0.0426 & 0.0170 & 0.2128 & 0.2800 & - \\
\hline $10 \%$ & 0.0394 & 0.0158 & 0.2168 & 0.2545 & $-9.09 \%$ \\
\hline $20 \%$ & 0.0368 & 0.0147 & 0.2205 & 0.2333 & $-16.67 \%$ \\
\hline $30 \%$ & 0.0345 & 0.0138 & 0.2240 & 0.2154 & $-23.08 \%$ \\
\hline $40 \%$ & 0.0325 & 0.0130 & 0.2273 & 0.2000 & $-28.57 \%$ \\
\hline $50 \%$ & 0.0342 & 0.0137 & 0.2563 & 0.1867 & $-33.33 \%$ \\
\hline $60 \%$ & 0.0325 & 0.0130 & 0.2597 & 0.1750 & $-37.50 \%$ \\
\hline $70 \%$ & 0.0309 & 0.0124 & 0.2630 & 0.1647 & $-41.18 \%$ \\
\hline $80 \%$ & 0.0296 & 0.0118 & 0.2661 & 0.1556 & $-44.44 \%$ \\
\hline $90 \%$ & 0.0283 & 0.0113 & 0.2691 & 0.1474 & $-47.37 \%$ \\
\hline $100 \%$ & 0.0272 & 0.0109 & 0.2720 & 0.1400 & $-50.00 \%$ \\
\hline $110 \%$ & 0.0262 & 0.0105 & 0.2748 & 0.1333 & $-52.38 \%$ \\
\hline $120 \%$ & 0.0252 & 0.0101 & 0.2775 & 0.1273 & $-54.55 \%$ \\
\hline $130 \%$ & 0.0244 & 0.0097 & 0.2801 & 0.1217 & $-56.52 \%$ \\
\hline $140 \%$ & 0.0236 & 0.0094 & 0.2826 & 0.1167 & $-58.33 \%$ \\
\hline $150 \%$ & 0.0228 & 0.0091 & 0.2851 & 0.1120 & $-60.00 \%$ \\
\hline $160 \%$ & 0.0221 & 0.0088 & 0.2875 & 0.1077 & $-61.54 \%$ \\
\hline $170 \%$ & 0.0215 & 0.0086 & 0.2899 & 0.1037 & $-62.96 \%$ \\
\hline $180 \%$ & 0.0209 & 0.0083 & 0.2922 & 0.1000 & $-64.29 \%$ \\
\hline $190 \%$ & 0.0203 & 0.0081 & 0.2944 & 0.0966 & $-65.52 \%$ \\
\hline $200 \%$ & 0.0198 & 0.0079 & 0.2967 & 0.0933 & $-66.67 \%$ \\
\hline
\end{tabular}

